\title{
A LOGIC APPROACH IN THE SIMPLEX METHOD OF LINEAR PROGRAMMING*
}

\author{
EDIP BUYUKKOCA**, IKUHo YAMADA AND IKURo KUSABA*** \\ Department of Industrial Chemistry, Nagoya Institute of Technology, Nagoya
}

The purpose of this paper is to show a logic of direct approach for the simplex method on L.P.

From the characteristics of the objective function and the constraints, L.P. problems can be classified as follows:

Form

\begin{tabular}{lll}
\multicolumn{1}{c}{ Form } & $\begin{array}{l}\text { Objective } \\
\text { function } \\
\text { Ntandard }\end{array}$ & Max $c^{T} x$ \\
Type I & $\operatorname{Max} c^{T} x$ & $A x>b, x>0$ \\
Type II & $\operatorname{Min} c^{T} x$ & $A x<b, x>0$ \\
Type III & $\operatorname{Min} c^{T} x$ & $A x<b, x>0$ \\
Type IV & $\operatorname{Max} c^{T} x$ & $A x \geqslant \leqslant b, x>0$ \\
Type V & $\operatorname{Min} c^{T} x$ & $A x \geqslant \leqslant b, x>0$
\end{tabular}

A) Standard

B) Nonstandard

Preliminaries: A linear programming model has been constructed from three parts. The influence of characteristics of each part can be considered as in the following order: objective function, R.H.S. (right-hand side) and left-hand side. The proposed method involves two concepts with respect to criteria. The first concept is that the direction of objective function should be always kept in an objective policy, and is characterized by the coefficient of objective function. The second concept is related to the determination of the optimal condition. These concepts are connected with the definition of the key capacity factor $\Psi b$.

$$
\Psi b \equiv \text { value of R.H.S. } / \sum_{j=1}^{m} a_{i j}
$$

where $j$ is a constant chosen by characteristics of the objective function. These concepts are the main preliminaries of this method. Furthermore, additional preliminaries are shown as follows: 1) Let $b$ be a capacity for the optimum feasible solution. 2) The criterion of decision for each iteration is that all the capacities must be used for most profitable decision, and each decision is changed to the next one. 3) Let $\Delta c$ be the profit difference between two decisions. 4) The key capacity factor, which is a possibility to use the present capacities for the deci-

\footnotetext{
* Received on May 18, 1973

** Dept. of Chem. Eng., Technical University of Istanbul, Turkey

*** Dept. of Management Eng., Nagoya Inst. of Tech., Nagoya 干466 名古屋市昭和区御器所町

名古屋工業大学工業化学科 山田幾穂
}

sion, also helps to calculate the new capacities. Table 1 shows how to apply the main criteria of the concepts proposed, as well as the policy to solve all type of L.P. problems.

Steps of calculation procedure: 1- Convert the inequalities to equalities with nonnegative slack variables. 2- Determine the first feasible solution. The variables which make this feasible solution are called the basic set. 3- Choose the policy to solve the problems by Table 1 . This is the first speciality of the logical way of the present paper. 4- The feasible solution is now tested for optimality. This is the second speciality, which relates to the key capacity. The profit difference $\Delta c_{j}$ is evaluated by the following calculation.

$$
\Delta c_{j}=c_{j}-\sum_{i=1}^{m} a_{i j} c_{i} \quad(j=1, \ldots n)
$$

If one or more of $\Delta c_{j}$ is positive, the feasible solution is nonoptimal for the standard form, and Type I, IV of nonstandard form. If all $\Delta c_{j}$ are negative, the optimum solution has been found, and the solution terminates. If one or more of $\Delta c_{j}$ is negative, the feasible solution is nonoptimal for Type II, III and $\mathrm{V}$ of nonstandard form. If all $\Delta c_{j}$ are positive, the solution is found, and it terminates. 5- Determine new capacities and the coefficients of the problem in step 4. 6- Return to step 3, and continue until the optimum solution is obtained.

\section{Examination}

Example $1^{1)}$

$\operatorname{Max}\left(x_{1}-x_{2}\right)$

subject to

$$
\begin{aligned}
& 2 x_{1}-x_{2}<4 \\
& x_{1}-2 x_{2}<2 \\
& x_{1}+x_{2}>5
\end{aligned}
$$$$
x_{1}, x_{2}>0
$$

[Solution] This problem is solved by the standard from of L.P. mentioned in Table 1. 1- Step 1 leads

$$
\begin{aligned}
& 2 x_{1}-x_{2}+z_{1}=4 \\
& x_{1}-2 x_{2}+z_{2}=2 \\
& x_{1}+x_{2}+z_{3}=5
\end{aligned}
$$

2- Tableau I shows the first feasible solution. 3Choose the policy as shown in Tableau I denoting the mark $\uparrow$. 4- This problem means that all $\Delta c_{j}$ must be negative or zero, but there is one positive 
Table 1 Entering policy of the LP problem

Standard form of L.P. (A)

Nonstandard form of L.P. (B)

\begin{tabular}{llllll} 
& \multicolumn{1}{c}{ a) Type I } & b) Type II & c) Type III & d) Type IV \\
$\begin{array}{llll}\text { Lowest value of the } \\
\text { key capacity factor }\end{array}$ & $\begin{array}{l}\text { highest value of } \\
\text { the key capacity } \\
\text { factor }\end{array}$ & $\begin{array}{l}\text { highest value of } \\
\text { the key capcity } \\
\text { factor }\end{array}$ & $\begin{array}{l}\text { lowest value of } \\
\text { the key capacity } \\
\text { factor }\end{array}$ & area for the present capacity
\end{tabular}

biggest $\Delta c_{j}$

biggest $\Delta c_{j}$

smallest $\Delta c_{j}$

smallest $\Delta c_{j}$

biggest $\Delta c_{j}$

smallest $\Delta c_{j}$

$\Delta c_{j}$ in the tableau I. Therefore, this feasible solution is not the optimum solution. 5- From steps 4 and 5, Tableau II must be formed by choosing the key capacity factor as

$$
4 / 2=2, \quad 2 / 1=2, \quad 5 / 1=5, \quad \Psi b=2
$$

Consequently, as mentioned in Tableau II the value marked by $*$ is the key capacity factor. Then the capacities $(b)$ are rechosen by

$$
2, \quad 2-2 \times 1=0, \quad 5-2 \times 1=3
$$

Thus, the coefficients of variables are as follows:

$$
\begin{aligned}
x_{1} & =2 z_{1}+z_{2}+z_{3} \rightarrow z_{1}=(1 / 2) x_{1}-(1 / 2) z_{2}-(1 / 2) z_{3} \\
x_{2} & =-z_{1}-2 z_{2}+z_{3} \\
& =-(1 / 2) x_{1}+(1 / 2) z_{2}+(1 / 2) z_{3}-2 z_{2}+z_{3} \\
& =-(1 / 2) x_{1}-(3 / 2) z_{2}+(3 / 2) z_{3}
\end{aligned}
$$

Tableau II gives the optimum solution, because there is no positive $\Delta c_{j}$ in it. The solution is: $x_{1}=2, x_{2}=0$. The solution agrees with that by Amundson $^{1)}$, however, this method does not need any resolution.

Example 2

$$
\operatorname{Max}\left(3 x_{1}-2 x_{2}\right)
$$

subject to

$$
\begin{aligned}
& -x_{1}+2 x_{2}<8 \\
& x_{1}+10 x_{2}>10 \\
& (1 / 3) x_{1}+(1 / 2) x_{2}<5
\end{aligned} \quad x_{1}, x_{2}>0
$$

[Solution] This problem is solved by Type IV of the nonstandard form. 1- Step 1 leads

$$
\begin{aligned}
& -x_{1}+2 x_{2}+z_{1}=8 \\
& x_{1}+10 x_{2}-z_{2}=10 \\
& (1 / 3) x_{1}+(1 / 2) x_{2}+z_{3}=5
\end{aligned}
$$

2- Thus, Tableau III shows the feasible solution.

3- Choose the policy as shown by mark $\uparrow$ in Tableau III. 4- In this problem all $\Delta c_{j}$ must be negative or zero. But there is one positive $\Delta c_{j}$ in it. Therefore this feasible solution is not optimum. 5- From steps 4 and 5, Tableau IV must be formed by choosing

\begin{tabular}{|c|c|c|c|c|c|c|c|}
\hline$c_{i}$ & $z_{i}$ & $x_{1}$ & $x_{2}$ & $z_{1}$ & $z_{2}$ & \begin{tabular}{l|}
$z_{3}$ \\
\end{tabular} & $\mathrm{C}$ \\
\hline 0 & $z_{1}$ & 2 & -1 & \begin{tabular}{|l|} 
\\
\end{tabular} & 0 & \begin{tabular}{l|} 
\\
\end{tabular} & 4 \\
\hline 0 & $z_{2}$ & 1 & -2 & 0 & 1 & 0 & 2 \\
\hline \multirow[t]{4}{*}{0} & $z_{3}$ & 1 & 1 & 0 & 0 & 1 & 5 \\
\hline & $c_{j}$ & 1 & -1 & 0 & 0 & 0 & \\
\hline & $\sum_{j=1}^{m} a_{i j} c_{i}$ & 0 & 0 & 0 & 0 & 0 & \\
\hline & $\Delta c_{j}$ & 1 & -1 & 0 & 0 & 0 & \\
\hline
\end{tabular}
the key capacity factor as

\begin{tabular}{|c|c|c|c|c|c|c|c|}
\hline$c_{i}$ & $z_{i}$ & $x_{1}$ & $x_{2}$ & $z_{1}$ & $z_{2}$ & $z_{3}$ & $\mathrm{C}$ \\
\hline 1 & $z_{1}$ & 1 & $-1 / 2$ & $1 / 2$ & 0 & 0 & 2 \\
\hline 0 & $z_{2}$ & 0 & $-3 / 2$ & $-1 / 2$ & 1 & 0 & 0 \\
\hline 0 & $z_{3}$ & 0 & $3 / 2$ & $-1 / 2$ & 0 & 1 & 3 \\
\hline & $c_{j}$ & 1 & -1 & 0 & 0 & 0 & \\
\hline & $\sum_{j=1}^{m} a_{i j} c_{i}$ & 1 & $-1 / 2$ & $1 / 2$ & 2.0 & 0 & \\
\hline & $\Delta c_{j}$ & 0 & $-1 / 2$ & $-1 / 2$ & 0 & 0 & \\
\hline
\end{tabular}

$$
8 \times(-1)=-8, \quad(10 / 1)=10, \quad 5 \times(3 / 1)=15, \quad \Psi b=15
$$

\begin{tabular}{|c|c|c|c|c|c|c|c|}
\hline$c_{i}$ & $z_{i}$ & $x_{1}$ & $x_{2}$ & $z_{1}$ & $z_{2}$ & $z_{3}$ & $\mathrm{C}$ \\
\hline 0 & $z_{1}$ & -1 & 2 & 1 & 0 & 0 & 8 \\
\hline 0 & $z_{2}$ & 1 & 10 & 0 & -1 & 0 & 10 \\
\hline 0 & $z_{3}$ & $1 / 3$ & $1 / 2$ & 0 & 0 & 1 & 5 \\
\hline & $c^{T}$ & 3 & \begin{tabular}{|l|}
-2 \\
\end{tabular} & 0 & 0 & 0 & \\
\hline & $\sum_{j=1}^{m} a_{i j} c_{i}$ & 0 & 0 & 0 & | & 0 & \\
\hline & $\Delta c_{j}$ & 3 & -2 & 0 & 0 & 0 & \\
\hline
\end{tabular}

Thus, only $\Psi b=15$ is in valid area for all conditions of the problem (See Fig. 1). The new capacities (b) are as follows

\begin{tabular}{|c|c|c|c|c|c|c|c|}
\hline$c_{i}$ & $z_{i}$ & $x_{1}$ & $x_{2}$ & $z_{1}$ & $z_{2}$ & $z_{3}$ & C \\
\hline 0 & $z_{1}$ & 0 & $7 / 2$ & 1 & 0 & 3 & 23 \\
\hline 0 & $z_{2}$ & 0 & $3 / 2$ & 0 & -1 & -3 & -5 \\
\hline \multirow[t]{4}{*}{3} & $z_{3}$ & 1 & -2 & 0 & 0 & 3 & 15 \\
\hline & $c^{T}$ & 3 & -2 & 0 & 0 & 0 & \\
\hline & $\sum_{j=1}^{m} a_{i j} c_{i}$ & 3 & $9 / 2$ & 0 & 0 & 0 & \\
\hline & $\Delta c_{j}$ & 0 & $-13 / 2$ & 0 & 0 & -3 & \\
\hline
\end{tabular}

$$
\begin{gathered}
8-(-1)(15)=23 \\
10-(1)(15)=-5 \\
\Psi b=15
\end{gathered}
$$

Then

$$
z_{3}=3 x_{1}+3 z_{1}-3 z_{2}
$$

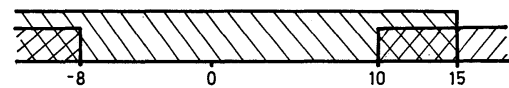

Fig. 1 Choosing of $\Psi b$ for Example 2 Tableau I

Tableau II

Tableau III

Tableau IV

$x_{2}=(7 / 2) z_{1}+(17 / 2) z_{2}+(3 / 2) x_{1}$

Tableau IV gives optimum solution, since no positive $\Delta c_{j}$ is in it. Finally, $x_{1}=15, x_{2}=0$

Hitherto two different approaches to solve L.P. problem by the simplex method involving the resolution of the degeneracy problem have been developed by several investigators ${ }^{2-4)}$. However, the present paper emphasises that when one uses the proposed logic way one never meets any degeneracy problem involving resolution procedure. Generally, the ordinary simplex method of L.P. is a dynamic trial and error way, the number of trials is almost the same as that of extreme points, and the solution converges between $m$ and $2 m$, where $m$ is the number of constraints. The logical way presented follows dynamic trial and error calculation procedure, but the number of iterations is always less than that by the ordinary simplex method.

\section{Acknowledgment}

The first author appreciates the financial support from the Japanese government, and he would like to acknowledge the continuing encouragement of Professor Karayalcin of the Department of Operation Research and Professor Cátaltas of the Department of Chemical Engineering of the Technical Univer- 
sity of Istanbul.

\section{Nomenclature}

$\begin{array}{ll}a_{i j} & =\text { coefficient of } x_{i j} \\ b_{i} & =\text { parameter of constraint } i \text { related to capacity [-] }\end{array}$

$c_{i} \quad=$ coefficient of objective function of $z_{i}$

$c_{j} \quad=$ coefficient of objective function of $x_{j}$

$\Delta c_{j} \quad=$ difference between $c_{j}$ and $\sum_{j=1}^{m} a_{i j} c_{i}$

$=$ number of constraints

$[-]$

$[-]$ $\boldsymbol{i}=$ constraint

$j \quad=$ real variable $\begin{array}{ll}m & =\text { number of constraints } \\ n & =\text { number of real variables }\end{array}$

$\begin{array}{ll}x_{j} & =\text { real variable } \\ z_{j} & =\text { slack variable }\end{array}$

$\begin{array}{ll}x_{j} & =\text { real variable } \\ z_{j} & =\text { slack variable }\end{array}$

$\langle$ Subscripts〉

\section{Literature Cited}

1) Amundson, Neal R.: "Mathematical Methods in Chemical Engineering, Matices and their Application", p. 105 Prentice-Hall Inc., Englewood Cliffs, N. J. (1966)

2) Charnes, A.: “Optimality and Degeneracy in Linear Programming", Economerica, Vol. 20, p. 160-70

[-] 3) Dantzig: "Linear Programming and Extensions", Princeton,

[-] University Press, Princeton, N.J. (1963)

4) Wolfe, P.: "A Technique for Solving Degeneracy in Linear Programming", RAND Corporation, Santa Monica, Calif., May (1962)

ERRATA TO VOL. 7, NOS. 1-3 (1974)

\begin{tabular}{|c|c|c|c|c|c|}
\hline No. & Page & Column & Line & erroneous & should read \\
\hline \multicolumn{6}{|c|}{ (b: bottom, $\mathrm{t}:$ top) } \\
\hline \multirow[t]{3}{*}{1} & 1 & 2 & $6 b$ & spectrat & spectra \\
\hline & 4 & 2 & $2 b$ & elucidated & elucidate \\
\hline & 7 & 1 & $8 \mathrm{~b}$ & Walti & Wälti \\
\hline 2 & 137 & 2 & $14 \mathrm{~b}$ & (1) & (13) \\
\hline \multirow[t]{8}{*}{3} & 158 & abstract & $2 \mathrm{t}$ & $W=W_{0} \exp \left[-\left(A / E_{0}\right)^{n}\right]$ & $W=W_{0} \exp \left[-(A / E)^{n}\right]$ \\
\hline & 161 & 2 & Eq. (4) & $P_{s}=P_{c} \exp \left(\frac{T-T_{c}}{T} \cdot \frac{\Delta H_{0}}{R T_{c}}\right)$ & $p_{s}=p_{c} \exp \left(\frac{T-T_{c}}{T} \cdot \frac{\Delta H_{0}}{R T_{c}}\right)$ \\
\hline & 163 & 1 & Eq. (11) & $0.26 \frac{y^{+3}}{R^{+2}}$ & $0.24 \frac{y^{+2}}{R^{+2}}$ \\
\hline & 163 & 2 & Eq. (13) & $f=\tau_{w}\left(\rho \bar{u}^{2} / 2\right)$ & $f=\tau_{w} /\left(\rho \bar{u}^{2} / 2\right)$ \\
\hline & 201 & 2 & $9 \mathrm{t}$ & almostp article-free & almost particle-free \\
\hline & 209 & 2 & Fig. 2 & $\mathrm{k}_{\mathrm{ob}} \mathrm{a}_{\mathrm{b}} / \varepsilon_{\mathrm{b}}[\mathrm{sec}]$ & $\mathrm{k}_{\mathrm{ob}} \mathrm{a}_{\mathrm{b}} / \varepsilon_{\mathrm{b}}\left[\mathrm{sec}^{-1}\right]$ \\
\hline & 212 & 2 & $11 \mathrm{t}$ & (197) & (1973) \\
\hline & 230 & 2 & $4 \& 6 t$ & $\sqrt{\left[\eta+\beta \eta+C_{e}\left(i \pi / 2 \omega_{0}\right)^{2}\right]^{2}-C_{e}\left(i \pi / \omega_{0}\right)^{2}}$ & $\sqrt{\left[\eta+\beta \eta+C_{e}\left(i \pi / 2 \omega_{0}\right)^{2}\right]^{2}-C_{e} \eta\left(i \pi / \omega_{0}\right)^{2}}$ \\
\hline
\end{tabular}

